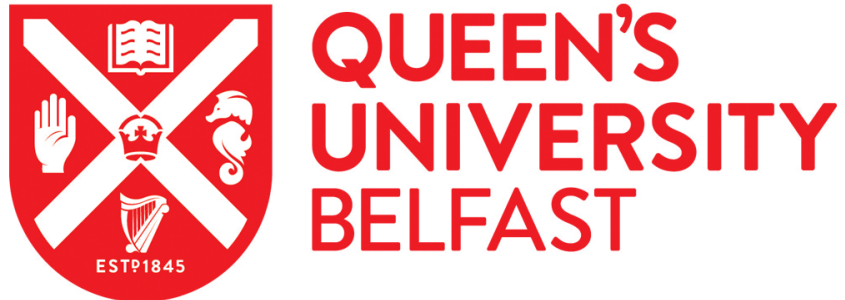

\section{Longitudinal associations between narcissism, mental toughness and school achievement}

\author{
Papageorgiou, K. A., Malanchini, M., Denovan, A., Clough, P. J., Shakeshaft, N., Schofield, K., \& Kovas, Y. \\ (2018). Longitudinal associations between narcissism, mental toughness and school achievement. Personality \\ and Individual Differences, 131, 105-110. https://doi.org/10.1016/j.paid.2018.04.024
}

Published in:

Personality and Individual Differences

\section{Document Version:}

Peer reviewed version

Queen's University Belfast - Research Portal:

Link to publication record in Queen's University Belfast Research Portal

\section{Publisher rights}

Copyright 2018 the authors.

This is an open access article published under a Creative Commons Attribution-NonCommercial-NoDerivs License

(https://creativecommons.org/licenses/by-nc-nd/4.0/), which permits distribution and reproduction for non-commercial purposes, provided the author and source are cited.

\section{General rights}

Copyright for the publications made accessible via the Queen's University Belfast Research Portal is retained by the author(s) and / or other copyright owners and it is a condition of accessing these publications that users recognise and abide by the legal requirements associated with these rights.

\section{Take down policy}

The Research Portal is Queen's institutional repository that provides access to Queen's research output. Every effort has been made to ensure that content in the Research Portal does not infringe any person's rights, or applicable UK laws. If you discover content in the Research Portal that you believe breaches copyright or violates any law, please contact openaccess@qub.ac.uk. 
NARCISSISM, MENTAL TOUGHNESS AND SCHOOL ACHIEVEMENT

Longitudinal Associations between Narcissism, Mental Toughness and School Achievement 


\begin{abstract}
Mental Toughness has been associated with optimal performance across diverse contexts including academic achievement. MT is positively associated with subclinical narcissism. Crosssectional research reported that high narcissism may contribute indirectly to enhanced positive outcomes, through MT. This study is the first to explore longitudinally the development of the association between MT, narcissism and achievement in a sample of adolescents. MT correlated positively with narcissism and predicted a small percentage of the variation in school achievement. Narcissism did not correlate significantly with school achievement. However, subclinical narcissism exerted a significant positive indirect effect on school achievement through MT. The findings suggest that the relationship between narcissism and MT could be one of the non-cognitive mechanisms that underlie individual variation in school achievement.
\end{abstract}

Keywords: longitudinal design, mental toughness, subclinical narcissism, school achievement. 


\subsection{Introduction}

There is increasing interest in studying the role of non-cognitive traits in contributing to variation in academic attainment across development (e.g. Dumfart \& Neubauer, 2016). Several non-cognitive traits have been identified as buffers against the negative impact of stressful situations on performance in education. These include grit (Duckworth, Peterson, Matthews, \& Kelly, 2007); motivation (Lepper, Corpus, \& Iyengar, 2005); resilience (McGeown, St ClairThompson, \& Clough, 2016); and hardiness (Kobasa, 1979). Mental Toughness (MT) has been suggested as a construct that may subsume the aforementioned concepts (see Bahmani et al., 2016).

\subsection{Mental Toughness, Learning and Educational Achievement}

MT is a personality trait that includes an array of positive characteristics such as perceiving challenge as an opportunity rather than a threat and feeling in control of life situations (Clough, Earle, \& Sewell, 2002). MT reflects an effective coping mechanism in reaction to stressors and it facilitates proactively seeking out opportunities for personal growth (St ClairThompson et al., 2015). MT correlates with personality traits that are established predictors of performance in diverse settings (Lin, Mutz, Clough, \& Papageorgiou, 2017). For example, a study reported positive correlations between MT, extraversion, openness to experience, agreeableness, and conscientiousness; and negative correlations between MT and neuroticism (Horsburgh, Schermer, Veselka, \& Vernon, 2009). Another study showed evidence for the existence of a general factor of personality representing high levels of MT, extraversion, and conscientiousness as well as low levels of neuroticism (Veselka, Schermer, Petrides, \& Vernon, 2009).

Clough and colleagues (2002) characterised MT as a composite of four (the 4Cs) strongly 
correlated but independent subcomponents: (1) control (life and emotion): the tendency to feel and act as if one is influential and keep anxieties in check; (2) commitment: the tendency to be deeply involved in pursuing goals despite difficulties that arise; (3) challenge: the tendency to see potential threats as opportunities for self-development and to continue to strive in changing environments; and (4) confidence (in abilities and interpersonal): the belief that one is a truly worthwhile person in spite of setbacks, and the ability to push oneself forward in social settings.

Previous research has shown that MT is an important concept for explaining individual differences in learning and educational performance (McGeown et al., 2016). For example, positive correlations were found between total MT, academic attainment $(r=.22)$, attendance $(r$ $=.22$; St Clair-Thompson et al., 2015), social inclusion $(r=.22)$ and social acceptance $(r=.38)$ in adolescents (St Clair-Thompson et al., 2015). Another study showed that MT was correlated negatively with oppositional behaviour $(r=-.23)$, inattention $(r=-.17)$ and hyperactivity $(r=$ .14) in adolescents (St Clair-Thompson et al., 2015).

Individual differences in MT also associate with individual variation in undergraduate students' performance in learning and education. For example, a study reported positive correlations between MT, grades and progression $(r=.31$ and $r=.25$, respectively; Crust et al., 2014) in undergraduate students. Another study reported that the 4Cs were positively associated with self-esteem $(r=.23$ for the subscale of control of emotions to .83 for the subscale of confidence) and college adjustment ( $r=.19$ to .70$)$; and negatively associated with school concerns ( $r=-.27$ to -.52$)$ in undergraduate students (St Clair-Thompson et al., 2015). The particularly high correlation between self-esteem and confidence (reported in St Clair-Thomson et al., 2015) is to be expected and it has been acknowledged by a number of authors and 
NARCISSISM, MENTAL TOUGHNESS AND SCHOOL ACHIEVEMENT

approaches (e.g. Cashmore, 2002; Crust, 2008). However, MT represents a number of additional (to self-esteem) psychological constructs including Seeking out challenge; Motivation to achieve; Persistence and Resilience (Clough et al., 2002).

Recently a study explored the association between MT and academic grades and attendance in a sample of university students. Commitment and control together accounted for $16.5 \%$ of the variance in total average grade (Lin et al., 2017). These studies suggest that MT is an important trait in relation to educational outcomes with implications for educational practice.

\subsection{Narcissism and Mental Toughness}

Subclinical narcissism includes facets retained from the clinical syndrome, namely grandiosity, entitlement, dominance, and superiority (Paulhus \& Williams, 2002). Previous studies suggested that narcissism might be unique among the DT traits in that, it encapsulates to a larger extent (in comparison to psychopathy and Machiavellianism), prosocial and adaptive behaviours (e.g. Veselka et al., 2012). Petrides et al. (2011) used a sample of twins and reported that — unlike psychopathy and Machiavellianism—narcissism correlates positively $(r=.20$ for twin 1 and $r=.22$ for twin 2) with emotional intelligence. The authors suggested that the heightened sense of self-worth may render a narcissist optimistic, motivated, assertive, and successful in relationships (Petrides et al., 2011).

Three studies have explored the relationship between subclinical narcissism and MT in adults (Onley et al., 2013; Sabouri et al., 2015; Papageorgiou, Wong, \& Clough, 2017). All three studies reported significant and positive associations between the two traits $(r=.13-.21$ between the $4 \mathrm{Cs}$ and narcissism; $r=.50$ for total MT and narcissism; $r=.21$ for total MT and narcissism, respectively). Furthermore, Papageorgiou et al. (2017) showed that, despite being 
part of the dark triad, narcissism exerted a significant negative indirect effect on both psychopathy and Machiavellianism through MT. This statistical model suggests that subclinical narcissism could increase MT contributing indirectly to positive outcomes.

\subsection{The Current Study}

The current study aimed to: (1) Extend previous findings, derived from adult samples, on the association between subclinical narcissism and MT in an adolescent sample; (2) Explore longitudinally the degree to which individual differences in MT and subclinical narcissism predict individual variation in school achievement; (3) Test a mediation model suggesting that narcissism increases MT, which subsequently contributes to higher school achievement. We hypothesised that:

1. MT will correlate positively with subclinical narcissism in adolescence.

2. MT and subclinical narcissism will correlate positively with school achievement.

3. MT, narcissism and achievement will associate to each other longitudinally and will show high stability over time.

4. Narcissism will exert a positive indirect effect on school achievement through MT.

\subsection{Method}

\subsection{Sample}

Participants are part of the Multi-Cohort Investigation into Learning and Educational Success (MILES). Wave 1 and Wave $2((N=927$ and $N=561$, respectively after data cleaning and screening) include students recruited from three different Italian high schools in the Milan Province. The present investigation includes students who participated in MILES at both wave 1 
(March 2016) and wave 2 (June 2016). In total 339 students took part in both collection waves (54\% females). Participants' ages ranged between 14 and $21(M=15.63, S E=1.40$, in wave 1 and $M=15.83, S E=1.40$, in wave 2). Students with a diagnosis of learning difficulties were excluded from the current analyses. MILES received ethical approval from XXXXXXXXXX and the parents' and teachers' committees of every school that approved the MILES protocol.

\subsection{Procedure}

All students were invited to take part in the study. The data were collected online using the forepsyte.com online platform (www.forepsyte.com). Students took part in both testing sessions at home or on the school's computers after classes. Participants were given an individualised ID, which they used to access the web study. The ID codes and corresponding names are stored in a separate secure server from the rest of the data. An information sheet, consent form and debrief form were included at both collection waves. The first wave lasted around 90 minutes; the second wave around 45 minutes.

\subsection{Measures}

2.3.1 Mental Toughness. The newly developed ten-item Mental Toughness Questionnaire (MTQ-10) has been used to assess total MT at wave 1 and wave 2. Originally, a 12-item measure derived by taking the two highest line adding items of the MTQ48 in each of the six sub scales. We then performed a Confirmatory Factor Analysis (CFA) on the 12-item measure and resulted in the 10-item version due to poor factor loading for two of the 12 items. The initial CFA on the resultant 12 items from EFA provided unsatisfactory datamodel fit on all indices but SRMR, $\chi 2(54, N=343)=185.87, p<.001, C F I=.82, I F I=.82$, $S R M R=.07, R M S E A=.09(\mathrm{CI}$ of .08 to .11$)$. An inspection of factor loadings revealed that item 
7 and item 11 loaded poorly on the general factor (.27 and .22 respectively), and below the recommended threshold of .32 (see Tabachnick \& Fidell, 2001). Removal of these items resulted in an improved model fit. The statistical analysis that was conducted to validate this new measure is described in detail in the Supplementary Material.

The MTQ-10 has an average completion time of 5 minutes with responses to its 10 items given on a 5-point Likert scale anchored at $1=$ strongly disagree and $5=$ strongly agree. Three items are reverse coded; the MT score represents the average score of the 10 items. Example item include "I generally cope well with any problems that occur".

2.3.2 Narcissism. The Short Dark Triad questionnaire (SD3) assesses subclinical narcissism, subclinical psychopathy and Machiavellianism and it has high reliability and validity, including construct validity and external validity (Jones \& Paulhus, 2014). The SD3 includes 27 items, 9 for each scale with responses given on a 5-point Likert scale, with $1=$ strongly disagree and 5 strongly agree. We used only the 9 items that assess subclinical narcissism. Example items include: "People see me as a natural leader". The score for the subscale represents the average score of the 9 corresponding items.

2.3.3 School Grades. Students reported their grades in mathematics, literacy (Italian) and second language at the end of the first term (wave 1) and the second term (wave 2). Students' grades ranged from 4 to 10, where 10 indicated the highest possible grade, 6 represented pass, and 4 indicated a grade of 4 or lower. A mean composite score of the grades reported in mathematics, literacy and second language was created as a measure of overall school achievement. Self-reported grades are regarded as a reliable measure of school achievement (Kuncel, Crede, \& Thomas, 2005). 
2.3.4 Cognitive Ability Measures. Students' cognitive ability was used as a covariate in the analyses. A 30-item online version of the Raven's Progressive Matrices test (Raven, Court, \& Raven, 1996) was administered to assess non-verbal reasoning. The items were arranged in increasing level of difficulty. A discontinue rule was applied so that after three consecutively incorrect responses in one subsection, participants were re-directed to the next subsection.

The newly developed Italian Vocabulary Test (IVT-80; Malanchini et al., in preparation) was used to assess verbal ability. The test consisted of 80 items and it is loosely based on the Mill Hill vocabulary test (Raven, Raven, \& Court, 1998). For every item, participants were presented with a word, and they were asked to select a synonym of that word, out of six options. Only one option was the correct one. The items were presented in order of frequency in the written Italian language, from words appearing more frequently, to words with appearing less frequently. For example, the word "Motive" was presented together with six possible synonyms: (a) leader, (b) activity, (c) change, (d) motion, and (e) reason - with option 'e' being the correct answer. A short version of the IVT including 35 items (IVT-35) was included at wave 2. The IVT showed good test-retest correlation over 4 months $(r=.66, N=339)$. The test and the reduced version both showed reasonable external validity as they shared moderate correlations with literacy school achievement $(r=.36, N=922$ at wave 1 ; and $r=.40, N=522$ at wave 2) and non-verbal reasoning $(r=.42, N=922)$. A mean composite score of the two tests was taken as an index of cognitive ability.

\subsection{Results}

\subsection{Descriptive Statistics and Associations between Mental Toughness, Narcissism and}

\section{School Achievement}


Descriptive statistics for MT, subclinical narcissism, school grades and school achievement are presented in Table S1 in the Supplementary Material. Table 1 presents testretest reliabilities for MT, subclinical narcissism, school grades and school achievement; and correlations between school grades for wave 1 and wave 2, respectively.

\section{Table 1 should be placed here}

Partial correlations (controlling for age and sex) showed that subclinical narcissism (wave 1) correlated positively with MT at wave $1(r=.38, p<.001,95 \%$ CI $[0.28,0.47])$. Subclinical narcissism (wave 2) correlated positively with MT at wave $2(r=.34, p<.001,95 \%$ CI $[0.23,0.45])$.

Multiple linear regression (controlling for age, sex and cognitive ability) was used to explore the associations between MT and narcissism at wave 1 and wave 2 with school achievement (wave 1 and wave 2, respectively). Longitudinal associations between MT (wave 1) with grades in mathematics (wave 2), literacy (wave 2) and second language (wave 2); and between narcissism (wave 1) with grades in mathematics (wave 2), literacy (wave 2) and second language (wave 2) are presented in the supplementary material in Tables S2 and S3, respectively.

MT at wave 1 was associated significantly with school achievement at wave $1(\beta=.10$, $\left.R^{2}=.01, p<.05\right)$. MT at wave 2 was associated significantly with school achievement at wave 2 $\left(\beta=.13, R^{2}=.016, p<.05\right)$. MT at wave 1 was associated significantly with school achievement at wave $2\left(\beta=.11, R^{2}=.012, p<.05\right)$. When all covariates were excluded from the model, the predictive value of MT at wave 1 on school achievement at wave $2 \operatorname{increased}\left(\beta=.16, R^{2}=.026\right.$, $p<.01$ ). When cognitive ability only was excluded from the model, the predictive value of MT at wave 1 on school achievement at wave 2 increased significantly $\left(\beta=.19, R^{2}=.032, p<.01\right)$. 
Narcissism at wave 1 was not associated significantly with school achievement at wave $1(\beta=$ $\left..02, R^{2}=.00, p=.67\right)$. Narcissism at wave 2 was not associated significantly with school achievement at wave $2\left(\beta=.009, R^{2}=.00, p=.85\right)$. Narcissism at wave 1 was not associated significantly with school achievement at wave $2\left(\beta=-.03, R^{2}=.001, p=.55\right)$.

\section{Table 2 should be placed here}

\subsection{Cross-lagged Analysis}

Figure 1 presents a cross-lagged model exploring the longitudinal relations between narcissism, MT and school achievement across the two collection waves. All variables were age regressed and standardised prior to model fitting. The model was a good fit for the data $(C F I=$ $1.00, T L I=1.00, R M S E A=.000, S R M R=.00)$. MT was found to be stable over time $(\beta=.727, p$ $<.001)$, and strong stability was also observed for school achievement $(\beta=.822, p<.001)$ and narcissism $(\beta=.685, p<.001)$. The concurrent relation between MT and narcissism at wave 1 was moderate $(r=.424, p<.001)$. The two variables also shared a modest correlation at wave 2 beyond their correlation at wave $1(r=.232, p<.001)$. The correlation between MT and achievement at wave 1 was weak but significant $(r=.147, p<.001)$, and the two constructs shared a weak correlation at wave $2(r=.138, p<.01)$. Narcissism and achievement were not correlated at wave 1 , but they shared a weak association at wave $2(r=.135, p<.01)$.

Figure 1 should be placed here

\subsection{Mediation Effect of Mental Toughness on Narcissism and School Achievement}

The absence of a direct association between narcissism and achievement does not preclude the possibility that they are indirectly associated though their mutual relation with MT. Figure 2 illustrates our proposed mediation model: In line with the hypothesis, the indirect effect 
of narcissism (Wave 1) on school achievement (Wave 2), through individual differences in MT

(Wave 2), was positive and statistically significant $(b=0.08, S E=0.03,95 \%$ CI $[0.032,0.162]$ ).

\section{Figure 2 should be placed here}

\subsection{Discussion}

The present study explored longitudinally the contribution of MT and subclinical narcissism in educational achievement. The results extended previous cross-sectional findings in adult samples (e.g. Papageorgiou et al., 2017) showing a positive and moderate association between MT and subclinical narcissism, across both collection waves, in an adolescent sample. This finding provides further support to previous evidence (see for example, Onley et al., 2013) indicating that narcissism encapsulates prosocial and adaptive behaviours.

The results also showed that MT associates positively with school achievement. Additional analysis on the association between MT and school grades showed that MT associates more strongly with school grades in literacy than in mathematics and foreign language. This finding requires further investigation as it suggests that MT may be more relevant to certain aspects of academic attainment (such as in literacy) as compared to others (such as in mathematics). However, the variance in school achievement and grades that was explained by MT was very small, which poses difficulties in terms of making inferences about the practical value of these results. It is possible that non-cognitive traits, such as MT, may be stronger predictors of academic performance in higher education in comparison to lower levels of education. This could be due to the fact that university samples tend to exhibit less individual variation in intellectual ability as a result of students being selected on the basis of similar academic performance in high school (Furnham, Chamorro-Premuzic, \& McDougall, 2002). 
We do think however that MT has an important role to play in school achievement. A possible explanation for the difference between the current findings and previous research is differences in the measures that were used in this study and in previous studies. Specifically, the MTQ-10 may not capture the full amount of individual variation on MT offering lower explanatory power in relation to performance outcome. More importantly, however, we think that the scale of self-reported school grades is not sensitive enough to capture the full amount of variation that exists in the lower end of the distribution (the scale ranges from 4 to 10 where 4 represents any score from 0 to 4 ). Future studies could assess longitudinally total MT and the 4Cs and employ additional measures of school achievement in order to test the predictive power of MT on school performance.

Cross-lagged analyses showed that MT, narcissism and achievement were all highly stable over time, which is indicative of the reliability of these constructs. The correlations between measures were significant beyond those observed at wave 1; this finding may suggest that the observed associations grow over time. The cross-lagged links between all constructs were not significant. This suggests that, even if the associations between MT, narcissism and achievement grow over time; this growth is not a function of their direct mutual influences on each other. Oher factors, for example conscientiousness and openness to experience may influence the longitudinal association between MT and narcissism.

Mediation analysis showed that subclinical narcissism was positively associated with MT, which in turn was associated with higher school achievement. This is in line with recent findings (see Papageorgiou et al., 2017) suggesting that subclinical narcissism may increase MT, a trait that is relevant across achievement contexts, contributing indirectly to positive outcomes. Future studies could explore the role of MT and narcissism in other aspects of life, such as for 
example relationships, career aspirations and professional satisfaction.

The findings of the present research should be interpreted in light of some limitations. Responses in self-reported data may be influenced by common-method variance (Podsakoff, MacKenzie, Lee, \& Podsakoff, 2003) and social desirability, particularly in the context of the assessment of a "dark" trait (narcissism). Data collection from multiple raters could enhance the validity of the results. Moreover, scores for narcissism obtained using the SD3 might be biased towards assessing narcissism as a prosocial trait, linked to healthy self-esteem, rather than assessing the antisocial aspects of narcissism. Maples, Lamkin and Miller (2014) suggested that the SD3 narcissism scale measures primarily the grandiose aspects of this construct; while other short measures of this trait, such as the Dirty Dozen (Jonason \& Webster, 2010) might capture both vulnerable and grandiose features of narcissism. Finally, the generalizability of the findings might be limited to the educational system of the country from which the sample has derived; future studies could attempt to replicate the results using cross-cultural data.

McGeown et al. (2016) have proposed recently that future research focusing on MT should make efforts to overcome some of the methodological weaknesses (e.g. lack of longitudinal data) to allow a greater and more comprehensive understanding of this concept within education. The current study presents novel findings on the stability of individual differences in MT and subclinical narcissism over the course of a school year. The findings do not provide strong evidence for excluding subclinical narcissism from the dark triad of personality traits. However, the notion that scoring high on subclinical narcissism may increase school performance, through MT, supports the idea of studying the contextual adaptive and maladaptive aspects of traits; instead of focusing on rigid dichotomies between prosocial versus socially malevolent personality traits. 


\section{References}

Clough, P., Earle, K., \& Sewell, D. (2002). Mental toughness: The concept and its measurement. In I. M. Cockerill (Ed.), Solutions in sport psychology (pp. 32-43). Boston, MA: Cengage Learning.

Cashmore, E. (2002) Sport Psychology: The Key Concepts. Routledge: London

Crust, L. (2008). A review and conceptual re-examination of mental toughness: Implications for future researchers. Personality and Individual Differences, 45 (7), 576-583

Crust, L., Earle, K., Perry, J., Earle, F., Clough, A., \& Clough, P. J. (2014). Mental toughness in higher education: Relationships with achievement and progression in first-year university sports students. Personality and Individual Differences, 69, 87-91.

Crust, L., \& Clough, P. J. (2011). Developing mental toughness: from research to practice. Journal of Sport Psychology in Action, 2(1), 21-32.

Duckworth, A. L., Peterson, C., Matthews, M. D., \& Kelly, D. R. (2007). Grit: perseverance and passion for long-term goals. Journal of Personality and Social psychology, 92(6), 10871101.

Dumfart, B., \& Neubauer, A. C. (2016). Conscientiousness is the most powerful noncognitive predictor of school achievement in adolescents. Journal of Individual Differences, 37(1), $8-15$.

Furnham, A., Hughes, D. J., \& Marshall, E. (2013). Creativity, OCD, narcissism and the Big Five. Thinking Skills and Creativity, 10, 91-98.

Jonason, P. K., \& Webster, G. D. (2010). The Dirty Dozen: A concise measure of the dark tdad. Psychological Assessment, 22, 420-432.doi:10.1037/a0019265

Jones, D. N., \&Paulhus, D. L. (2014). Introducing the Short Dark Triad (SD3) A Brief Measure of Dark Personality Traits. Assessment, 21(1), 28-41. 
Kobasa, S. C. (1979). Stressful life events, personality, and health: an inquiry into hardiness. Journal of Personality and Social Psychology, 37(1), 1-11.

Kuncel, N. R., Crede, M., \& Thomas, L. L. (2005). The validity of self-reported grade point averages, class ranks, and test scores: A meta-analysis and review of the literature. Review of Educational Research, 75(1), 63-82.

Lepper, M. R., Corpus, J. H., \& Iyengar, S. S. (2005). Intrinsic and extrinsic motivational orientations in the classroom: Age differences and academic correlates. Journal of Educational Psychology, 97(2), 184-196.

Lin, Y., Clough, P. J., Welch, J., \& Papageorgiou, K. A. (2017). Individual differences in mental toughness associate with academic performance and income. Personality and Individual Differences, 113, 178-183.

Lin, Y., Mutz, J., Clough, P. J., \& Papageorgiou, K. A. (2017). Mental Toughness and Individual Differences in Learning, Educational and Work Performance, Psychological Well-being, and Personality: A Systematic Review. Frontiers in Psychology, 8. doi: 10.3389/fpsyg.2017.01345

Malanchini, M., Malanchini, M., Shakeshaft, N., \& Schofield, K. (in preparation). The reliability and validity of a new measure of acquired verbal knowledge: the Italian Online Vocabulary Test.

Maples, J. L., Lamkin, J., \& Miller, J. D. (2014). A test of two brief measures of the dark triad: The dirty dozen and short dark triad. Psychological assessment, 26(1), 326.

McGeown, S. P., St Clair-Thompson, H., \& Clough, P. (2016). The study of non-cognitive attributes in education: Proposing the mental toughness framework. Educational Review, 68(1), 96-113. 
Onley, M., Veselka, L., Schermer, J. A., \& Vernon, P. A. (2013). Survival of the Scheming: A Genetically Informed Link Between the Dark Triad and Mental Toughness. Twin Research and Human Genetics, 16(06), 1087-1095.

Papageorgiou, KA., Wong, B., \& Clough, P. (2017). Beyond Good and Evil: Exploring the Mediating Role of Mental Toughness on the Dark Triad of Personality Traits. Personality and Individual Differences, 119, 19-23.

Petrides, K. V., Vernon, P. A., Schermer, J. A., \& Veselka, L. (2011). Trait emotional intelligence and the dark triad traits of personality. Twin Research and Human Genetics, 14(01), 35-41.

Podsakoff, P. M., MacKenzie, S. B., Lee, J.-Y., \& Podsakoff, N. P. (2003). Common method biases in behavioral research: a critical review of the literature and recommended remedies. Journal of Applied Psychology, 88(5), 879-903.

Raven, J., Raven, J. C., \& Court, J. H. (1998). Advanced Progressive Matrices. Oxford, UK7 Oxford Psychologists Press.

Raven, J. C., Court, J. H., \& Raven, J. (1996). Raven matrices progressivas manual. Madrid: Publicaciones De Psicologia Aplicada

Sabouri, S., Gerber, M., Bahmani, D. S., Lemola, S., Clough, P. J., Kalak, N., ... \& Brand, S. (2016). examining Dark Triad traits in relation to mental toughness and physical activity in young adults. Neuropsychiatric disease and treatment, 12, 229.

Sadeghi Bahmani, D., Hatzinger, M., Gerber, M., Lemola, S., Clough, P. J., Perren, S., ... \& Brand, S. (2016). The origins of mental toughness-prosocial behavior and low internalizing and externalizing problems at age 5 predict higher mental toughness scores 
at age 14. Frontiers in Psychology. Advance online publication. doi: 10.3389/fpsyg.2016.01221

St Clair-Thompson, H., Giles, R., McGeown, S. P., Putwain, D., Clough, P., \& Perry, J. (2016). Mental toughness and transitions to high school and to undergraduate study. Educational Psychology. Advance online publication.

http://dx.doi.org/10.1080/01443410.2016.1184746

St Clair-Thompson, H., Bugler, M., Robinson, J., Clough, P., McGeown, S. P., \& Perry, J. (2015). Mental toughness in education: Exploring relationships with attainment, attendance, behaviour and peer relationships. Educational Psychology 35(7), 886-907.

Tabachnick, B. G., \& Fidell, L. S. (2001). Using Multivariate Statistics (4th ed.). Boston, MA: Allyn and Bacon.

Veselka, L., Schermer, J. A., \& Vernon, P. A. (2012). The Dark Triad and an expanded framework of personality. Personality and Individual Differences, 53, 417-425. 